\title{
Cardiovascular Sympathetic Arousal in Response to Different Mental Stressors
}

\author{
M. MESTANIK ${ }^{1}$, A. MESTANIKOVA ${ }^{1}$, Z. VISNOVCOVA $^{1}$, A. CALKOVSKA $^{1}$, \\ I. TONHAJZEROVA ${ }^{1}$
}

${ }^{1}$ Department of Physiology and Martin Biomedical Centre, Jessenius Faculty of Medicine

in Martin, Comenius University in Bratislava, Martin, Slovak Republic

Received March 20, 2015

Accepted July 22, 2015

December 15, 2015

\section{Summary}

The altered regulation of autonomic response to mental stress can result in increased cardiovascular risk. The laboratory tests used to simulate the autonomic responses to real-life stressors do not necessarily induce generalized sympathetic activation; therefore, the assessment of regulatory outputs to different effector organs could be important. We aimed to study the cardiovascular sympathetic arousal in response to different mental stressors (Stroop test, mental arithmetic test) in 20 healthy students. The conceivable sympathetic vascular index - spectral power of low frequency band of systolic arterial pressure variability (LF-SAP) and novel potential cardiosympathetic index - symbolic dynamics heart rate variability index $0 \mathrm{~V} \%$ were evaluated. The heart and vessels responded differently to mental stress - while Stroop test induced increase of both $0 \mathrm{~V} \%$ and LF-SAP indices suggesting complex sympathetic arousal, mental arithmetic test evoked only $0 \mathrm{~V} \%$ increase compared to baseline $(p<0.01, p<0.001, p<0.01$, respectively). Significantly greater reactivity of LF-SAP, OV\%, heart rate (HR) and mean arterial pressure (MAP) were found in response to Stroop test compared to mental arithmetic test potentially indicating the effect of different central processing (OV\%, LF-SAP: $p<0.001$; HR, MAP: $p<0.01$ ). The different effectors' sympathetic responses to cognitive stressors could provide novel important information regarding potential pathomechanisms of stress-related diseases.

\section{Key words}

Sympathetic nervous system - Mental stress - Systolic arterial pressure variability $\bullet$ Heart rate variability $\bullet$ Symbolic dynamics

\section{Corresponding author}

I. Tonhajzerova, Department of Physiology and Martin Biomedical Centre, Jessenius Faculty of Medicine in Martin, Comenius University in Bratislava, Mala Hora 4C, 03601 Martin, Slovak Republic. E-mail: tonhajzerova@jfmed.uniba.sk or ingridtonhajzerova@gmail.com

\section{Introduction}

The sympathetic nervous system is one of the key components of a nonlinear network of the stressrelated regulatory mechanisms. It mediates substantial part of allostatic processes regulating the perturbations of homeostasis and maintaining the stability of the organism through the changes of physiologic functions (McEwen 2007). This adaptive regulation affects multiple organ systems including cardiovascular system as a principal effector of the sympathetic central-peripheral pathway.

Sympathetic nervous system exerts direct effects on cardiovascular functions through cardiac nerves and vascular neural regulation and indirect effects by adrenal medullary influences and stimulation of renal juxtaglomerular cells (Charkoudian and Rabbitts 2009). Physiologically, these mechanisms play vital role in adaptation of hemodynamics to changing internal and external environment. However, they may become maladaptive after exposition to long-term, repetitive or excessive mental stress associated with altered sympathetic regulation, both exaggerated or diminished (Lovallo 2011). Detrimental effects on cardiovascular health result in increased risk of morbidity, e.g. elevated blood pressure (BP) or accelerated process of 
atherosclerosis (Chida and Steptoe 2010).

Formerly, the studies of the cardiovascular reactivity to stress were focused mainly on the changes of mean values of heart rate (HR) and BP (Falkner et al. 1979, Matthews et al. 1993). However, the computers' development enables to study cardiovascular regulatory mechanisms contributing to the HR and BP "beat-tobeat" variability, i.e. oscillations of HR/BP around their mean value. With regard to cardiac sympathetic activity, the low frequency component of heart rate variability (LF-HRV, 0.04-0.15 Hz) was used as a beta-adrenergic regulation marker and the ratio $\mathrm{LF} / \mathrm{HF}$ ( $\mathrm{HF}$ - high frequency band of HRV, $0.15-0.40 \mathrm{~Hz}$ ) as a parameter reflecting the relative sympathetic contribution to autonomic HR control (Pagani et al. 1986, Malliani et al. 1991, Lucini et al. 2002a). However, these assumptions are still controversial and extensively discussed. In this context, recent studies noted that LF-HRV is mainly determined by the activity of parasympathetic nervous system, and LF/HF ratio should not be considered as an unambiguous index of cardiac sympatho-vagal balance (Goldstein et al. 2011, Rahman et al. 2011, Reyes Del Paso 2013). Importantly, the non-linear HRV analysis symbolic dynamics - was found to be sensitive to the changes of the sympathovagal balance, and $0 \mathrm{~V} \%$ index could be associated with the conditions characterizing the sympathetic activation, such as orthostatic load (Porta et al. 2001, Guzzetti et al. 2005, Tonhajzerova et al. 2010). Nevertheless, our previous study firstly showed that $0 \mathrm{~V} \%$ index could reflect the beta-adrenergic activation during cognitive mental tests (Visnovcova et al. 2014). Therefore, this index might represent novel approach for noninvasive assessment of cardiac sympathetic regulation that is independent on the other effects, such as myocardial preload and afterload influencing frequently used beta-adrenergic index pre-ejection period (Newlin and Levenson 1979, Beauchaine et al. 2007). Notably, the studies related to the interaction "stress and $0 \mathrm{~V} \%$ index" are rare.

On the other hand, the alpha-adrenergic sympathetic vascular regulation is determined by spectral analysis of systolic arterial pressure variability in low frequency band (LF-SAP, 0.04-0.15 Hz) (Zhang et al. 2002). The LF-SAP was found to be higher in response to acute mental stress, such as Stroop task (e.g. Ginty et al. 2014). Additionally, the increased baseline values of LF-SAP and greater alpha-adrenergic response to orthostatic stress were previously found in hypertension or chronic psychosocial stress (Lucini et al. 2002b,
2005). It seems that BP analysis in low frequency band could represent a sensitive method for assessment of alpha-adrenergic sympathetic regulatory mechanisms, nevertheless, the myogenic vascular regulation could constitute other physiological mechanism contributing to LF-SAP (Zhang et al. 2002). However, detailed comparison of the effect of different cognitive tasks on vascular sympathetic regulation combined with simultaneous assessment of beta-adrenergic activity could offer novel complex view on cardiovascular response to stress.

Further, it was found that laboratory tests are able to simulate the patterns of reactions as found in real life and predict future cardiovascular risk status (Chida and Steptoe 2010, Zanstra and Johnston 2011). However, the stressors do not necessarily induce generalized response, and differences in activation degree can be found between distinct sympathetic outflows (Fechir et al. 2008). Therefore, the assessment of the sympathetic regulation of different effectors (i.e. heart and vessels) in response to different stressors may be of great importance.

Therefore, we aimed to study cardiovascular sympathetic reactivity in response to different mental stressors using linear and nonlinear analysis of blood pressure and heart rate variability in healthy young students. To the best of our knowledge, this is the first study to assess the complex potential cardio-sympathetic regulation indexed by symbolic dynamics $(0 \mathrm{~V} \%$ index) combined with evaluation of conceivable sympathetic vascular regulation indexed by LF-SAP in response to stress.

\section{Methods}

The study was approved by the Ethics Committee of Jessenius Faculty of Medicine in Martin, Comenius University in Bratislava in accordance with the Helsinki Declaration. All the participants gave informed written consent before participation in the study.

\section{Subjects}

The studied group consisted of 20 healthy nonobese medical students attending the $5^{\text {th }}$ year of Jessenius Faculty of Medicine (11 women, age 23.1 0.8 years, BMI $22.3 \pm 2.4 \mathrm{~kg} / \mathrm{m}^{2}$ ). Following exclusion criteria were strictly applied during enrollment of the subjects: underweight, overweight or obesity, smoking, alcohol and drug abuse, acute illness, history of chronic 
cardiovascular, respiratory, endocrinological, neurological, infectious diseases or mental disorders. The subjects were instructed to refrain from using substances which could affect the autonomic nervous system activity (e.g. caffeine, alcohol) at least $12 \mathrm{~h}$ before the examination.

\section{Procedure}

The examinations were performed under standard conditions in a sound-attenuated room and minimalization of stimuli, standard temperature $23{ }^{\circ} \mathrm{C}$ and humidity $45-55 \%$, in the morning between 9.00 a.m. - 12.30 p.m. after normal breakfast $2 \mathrm{~h}$ prior to the examination. At the beginning, anthropometric parameters were examined (InBody J10, Biospace, Korea) to exclude potential effect of weight abnormalities. The recording devices were set and calibrated and subjects were instructed to sit comfortably in a special armchair and not to speak or move unless necessary. In the context of the potential disturbance evoked by examining staff, the complete stress procedure was performed by the same one investigator-specialist, and only one participant was examined in the clinical laboratory. After $15 \mathrm{~min}$ required to avoid a potential stress effect of laboratory environment and examining person, the subjects remained in a sitting position. The continuous recording of RR-interval (VarCor PF8, Dimea, Czech Republic) and continuous beat-to-beat BP monitoring (Finometer PRO, Finapres medical systems, Netherlands) were performed in the following order: baseline phase, Stroop test, rest period, and mental arithmetic test. The duration of each phase was $6 \mathrm{~min}$. The participants were not informed about the order of the tests.

\section{Mental tasks}

Stroop color word test (Thought Technology, Ltd., Canada): The subjects were instructed to name the ink colors (green, yellow, orange, red, blue, purple) in which the words stimuli (name of the colors) were written and displayed on the screen. The meanings of the words were congruent or incongruent with the ink color. The metronome was used as a distracting element during the test.

Mental arithmetic test (Psychodiagnostic, Slovak Republic): During the test, three-digit numbers were displayed at the different random places on the screen. The task was based on the summation of three-digit numbers into one-digit numbers and making decision whether the final result is even or odd by pushing the keyboard arrow (left - odd, right - even). The metronome was applied during the test as a distracting sound.

\section{Evaluated parameters}

Two distinct components of sympathetic regulatory effects on cardiovascular system were studied - conceivable sympathetic vascular regulation indexed by LF-SAP, and complex potential cardio-sympathetic regulation indexed by symbolic dynamics index $0 \mathrm{~V} \%$.

The LF-SAP comprises rhythmic fluctuations of systolic BP in frequency range $0.04-0.15 \mathrm{~Hz}$, the socalled Mayer waves. The origin of this rhythmic variability has been explained mainly by two mechanisms: the pacemaker effect of the central nervous structures generating slow sympathetic nervous activity rhythms independently of peripheral afferent inputs and the baroreflex theory based on the studies with blockade of baroreflex loop resulting in marked reduction of Mayer waves (Julien 2006). The activity of alpha-adrenergic nerves is considered to be the major determinant of LF-SAP variations mediated by changes in peripheral vascular resistance, although intrinsic vasomotor rhythmicity affected by local mechanisms may play a significant role, as well (Zhang et al. 2002). Thus, spectral power of LF-SAP can be used as a conceivable marker of sympathetic vascular regulation.

Index $0 \mathrm{~V} \%$ is a parameter of symbolic dynamics method of HRV nonlinear analysis. It is based on the transformation of the time series into series of symbols which reflect the levels of the ranges of RR-intervals duration. Afterwards triplets of symbols (heartbeats) are classified into different patterns according to changes (variations) of the levels: $0 \mathrm{~V}$ (zero variation), $1 \mathrm{~V}$ (one variation), $2 \mathrm{LV}$ (two like variations) and 2UV (two unlike variations). Consequently, the rates of occurrence of these patterns are evaluated. The $0 \mathrm{~V}$ pattern is associated with conditions of sympathetic activation, thus it is considered to be a potential marker of beta-adrenergic sympathetic activity (Porta et al. 2001, Guzetti et al. 2005, Visnovcova et al. 2014). In addition, the average HR (beats per minute, bpm) and mean arterial BP (MAP, $\mathrm{mm} \mathrm{Hg}$ ) were calculated for each phase.

The reactivity of the LF-SAP, $0 \mathrm{~V} \%$, HR and MAP in response to mental stress tests compared to baseline was evaluated as a percentual change of the parameters using mathematical expression: [(value during test - baseline value) / baseline value] x $100(\%)$. 


\section{Statistical analysis}

Statistical analysis was performed using the statistical software package SYSTAT 10 for Windows (SSI, Richmond, CA, USA). The non-Gaussian/Gaussian distribution was ascertained by Lilliefors test. The spectral analysis parameter LF-SAP was logarithmically transformed for the analysis. Then, the Wilcoxon test was used for between-periods comparison of data with nonGaussian distribution and paired Student's t-test for data with Gaussian distribution. The probability $\mathrm{p}<0.05$ was considered as significant. The data are expressed as mean \pm SEM.

\section{Results}

The effect of the mental stress tests

The Stroop test evoked significant increase of mean values in both parameters - log LF-SAP and 0V\% - compared to baseline ( $\mathrm{p}<0.001, \mathrm{p}<0.01$, respectively; Fig. 1 and Fig. 2). Additionally, HR and MAP were significantly higher during the test compared to baseline (84.0 \pm 4.3 bpm vs. $72.1 \pm 2.4 \mathrm{bpm}, 96.4 \pm 2.4 \mathrm{~mm} \mathrm{Hg}$ vs. $87.4 \pm 1.8 \mathrm{~mm} \mathrm{Hg}$, respectively; $\mathrm{p}<0.001$ for both).

\section{$\log$ LF-SAP}

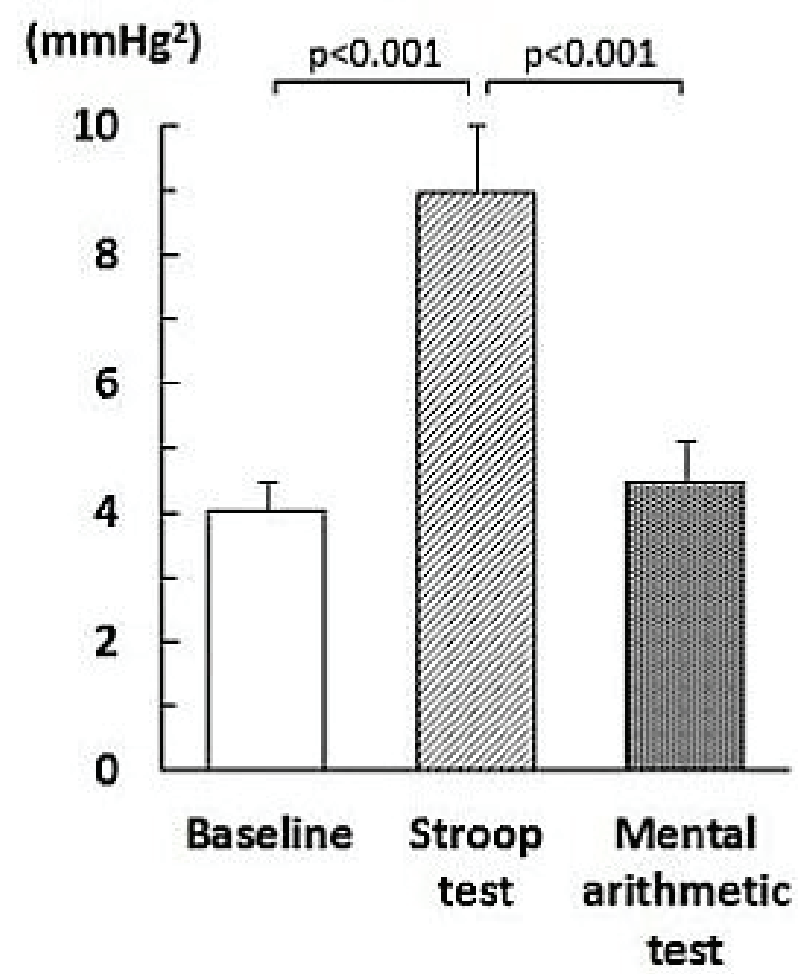

Fig. 1. Conceivable sympathetic vascular response to mental stressors indexed by spectral power of the low frequency band of systolic arterial pressure variability (LF-SAP).

\section{Index OV\%}

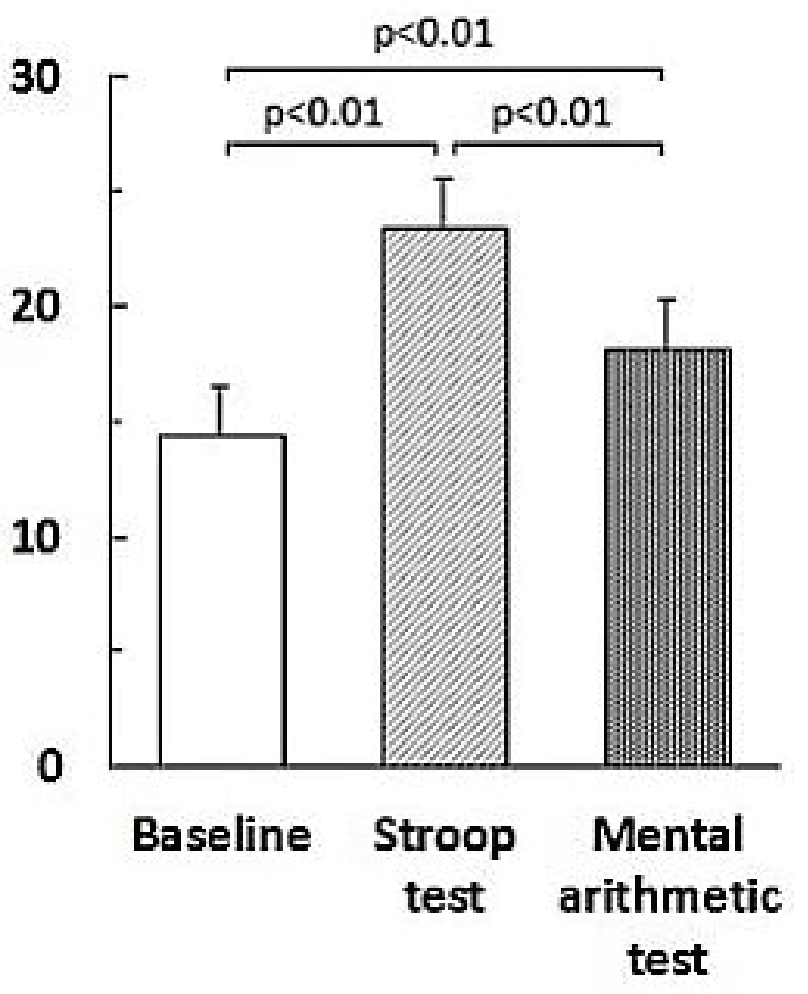

Fig. 2. Potential cardio-sympathetic response to mental stressors indexed by symbolic dynamics index $0 \mathrm{~V} \%$.

The mental arithmetic test evoked significant increase in the cardiac sympathetic index $0 \mathrm{~V} \%$ compared to baseline value ( $<<0.01$; Fig. 2$)$. Additionally, HR and MAP were significantly higher during the test compared to baseline $(79.4 \pm 3.7 \mathrm{bpm}$ vs. $72.1 \pm 2.4 \mathrm{bpm}, 92.6 \pm$ $2.5 \mathrm{~mm} \mathrm{Hg}$ vs. $87.4 \pm 1.8 \mathrm{~mm} \mathrm{Hg} ; \mathrm{p}<0.001, \quad \mathrm{p}<0.01$ respectively). No significant change was found in $\log$ LF-SAP (Fig. 1).

\section{Between-tests comparison}

Both parameters log LF-SAP and 0V\% were significantly higher in response to Stroop task compared to mental arithmetic test ( $\mathrm{p}<0.001, \mathrm{p}<0.01$, respectively; Fig. 1 and Fig. 2). The reactivity in log LF-SAP and 0V\% was significantly greater in response to Stroop test compared to mental arithmetic test $(p<0.001$ for both, Fig. 3). Additionally, mean values of HR and MAP were significantly higher during Stroop test compared to mental arithmetic test $(84.0 \pm 4.3 \mathrm{bpm}$ vs. $79.4 \pm 3.7 \mathrm{bpm}$, $96.4 \pm 2.4 \mathrm{~mm} \mathrm{Hg}$ vs. $92.6 \pm 2.5 \mathrm{~mm} \mathrm{Hg}$, respectively; $\mathrm{p}<0.01$ for both). Reactivity in HR and MAP was 
significantly greater in response to Stroop test compared to mental arithmetic test $(16.1 \pm 3.9 \%$ vs. $9.9 \pm 3.0 \%$, $10.4 \pm 1.8 \%$ vs. $6.0 \pm 1.9 \%$, respectively; $p<0.01$ for both).

\section{Reactivity}

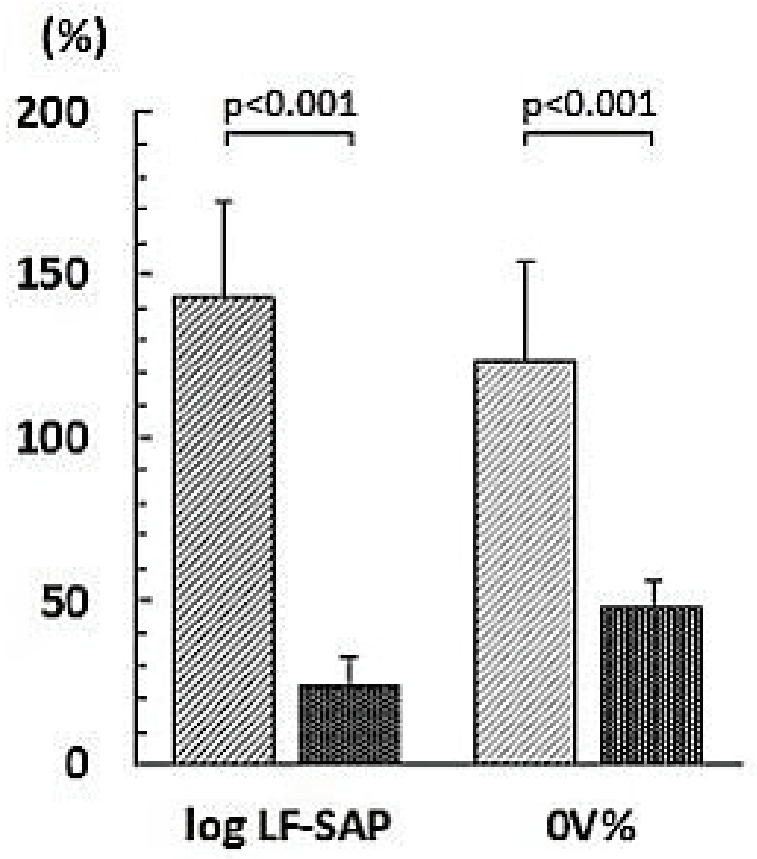

\section{WIIIIS Stroop test

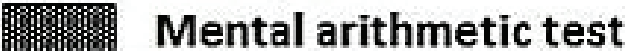

Fig. 3. Comparison of the reactivity of the conceivable sympathetic vascular index LF-SAP and potential cardiosympathetic index $0 \mathrm{~V} \%$ to mental stress tests. LF-SAP - spectral power in low frequency band of systolic arterial pressure

\section{Discussion}

The main finding of this study was that heart and vessels responded differently to cognitive mental tasks. The conceivable sympathetic vascular activation indexed by LF-SAP was induced only by the Stroop task, and cardio-sympathetic response indexed by $0 \mathrm{~V} \%$ was evoked by both cognitive tasks with greater activation in response to Stroop test. Moreover, the cognitive tasks lead to significant increase in HR and MAP with greater reaction during the Stroop test.

The autonomic regulation of the effector organs is achieved by multiple structures at all levels of the central nervous system forming a complex interconnected system called central autonomic network (Benarroch 1993). Importantly, these structures are also involved in the neural circuits regulating the executive, attentional and affective functions, forming a system coordinating the actual psychophysiological demands of these functional units with the modulation of the autonomic response to environmental challenges as suggested by neurovisceral integration model (Thayer and Lane 2000). For example, at the cortical level insula integrates the interoceptive stimuli with emotional and cognitive processing, modulates the autonomic regulation through connection with hypothalamus, and it is connected with anterior cingulate cortex (ACC) involved in control of sympathetic activation in response to cognitive and emotional load (Craig 2003, Beissner et al. 2013). Therefore, the patients with ACC lesion are not able to induce sympathetic activation adequate to workload demands (Critchley et al. 2003). From this context, the activation of ACC could represent an important mechanism contributing to sympathetic arousal in stress. Importantly, the autonomic-cardiovascular regulation is directly affected by the medial prefrontal cortex activity, as well. In particular, the ventral region inhibits the activation of the hypothalamus-pituitary-adrenal axis as well as the sympathetic nervous system, the dorsal division enhances the cardiovascular reaction to stress, probably due to modulation of the parasympathetic activity (Wager et al. 2009). Taken together, the cardiovascular sympathetic arousal induced by mental stress should be viewed as a result of complex interaction of several central regulatory mechanisms.

Our findings revealed both alpha- and betaadrenergic activation in response to Stroop test, but not in mental arithmetic test that was associated only with betaadrenergic reactivity. These results are in agreement with other study that revealed greater sympathetic response indexed by electrodermal activity, trapezius muscle electromyography, skin vasoconstriction and reduction of pulse wave transit time in Stroop test compared to mental arithmetic test despite the fact that mental arithmetic was subjectively more stressful (Fechir et al. 2008). The differences in sympathetic responses to these tasks could be potentially influenced by distinct central processing patterns and psychophysiological demands. During the Stroop test, the conflict of two competitive stimuli requires discrimination of the sources of information, task-relevant control of selective attention and choosing the response regardless of the automatic response tendencies (MacLeod and MacDonald 2000). The ACC seems to play a key role in this process - it is maximally activated during the Stroop performance and disruption of 
its activity by transcranial magnetic stimulation reduces the Stroop effect (MacLeod and MacDonald 2000, Hayward et al. 2004). Importantly, the cingulate cortex is also involved in the regulation of cardiovascular responses, particularly in the initiation of descendent efferent commands for the autonomic and subsequent cardiovascular reactions to stressors. The BP reactivity during the Stroop test correlated with the activity in ACC and individuals with larger BP reactions showed greater activation of the posterior cingulate cortex reciprocally connected with anterior divisions (Gianaros et al. 2005a,b). Thus, the ACC was suggested to represent possible functional neural correlate of exaggerated BP reactivity in response to Stroop test. Based on these findings, we could expect that the complex cardiovascular reaction to Stroop test in this study was significantly influenced by the activity of ACC.

Another important cortical region involved in selective attention regulation during the Stroop task is dorsolateral prefrontal cortex, which seems to be involved in top-down attentional control - representing and maintaining the attentional demands of the task (MacDonald et al. 2000). This was confirmed by the application of the repetitive transcranial magnetic stimulation over the dorsolateral prefrontal cortex significant decrease of the reaction time in the Stroop task was found, however, the interference effect remained unchanged (Vanderhasselt et al. 2006). We could assume that these central regulatory mechanisms could be considerably involved in the modulation of the cardiac beta-adrenergic and vascular alpha-adrenergic response to Stroop test in our study.

In contrast to Stroop test, we can suggest different neural mechanisms involved in mental arithmetic test that potentially influence cardiovascular sympathetic reactivity. Specifically, functional specialization of the left inferior parietal cortex associated with automatization of the simple arithmetic processes result in lower attentional demands exerted on the ACC and prefrontal cortex during the mathematic tasks (Rivera et al. 2005). Moreover, the role of dorsolateral prefrontal cortex in attention flexibility and inhibitory control is probably important only during difficult complex arithmetic processes and effortful controlled retrieval of the arithmetic facts (Rivera et al. 2005, Klein et al. 2013). On the contrary, the resolution of the simple addition tasks could be facilitated by an automatic retrieval of the arithmetic facts stored in long-term memory (Klein et al. 2013). Therefore, the higher cardiovascular reactivity in
Stroop test could be induced by the effect of more attention-demanding task resulting in more complex central processing compared to automatic cognitive processing associated with mental arithmetic.

Secondly, we could speculate about the effect of verbalization on the cardiovascular reactivity during verbal (Stroop) and nonverbal (arithmetic) tasks. In Stroop test, Boutcher and Boutcher (2006) revealed significantly greater HR and MAP in verbalized form compared to nonverbal Stroop test. Moreover, participants perceived verbal and nonverbal versions to be similarly difficult and attention demanding, therefore, the higher autonomic reactivity could be influenced by the effect of vocalization motor response. In contrast, other studies found no differences in HR and MAP during verbal and nonverbal Stroop test and mental arithmetic test suggesting that physiological components of vocalization do not affect the cardiovascular response to task (Seraganian et al. 1997, Barbosa et al. 2010). From this context, the effect of verbalization is still unclear. We suggest that the possible influence of this mechanism should be taken into account in the interpretation of our findings.

Moreover, our findings of cardiovascular reactivity to cognitive mental stressors could be also influenced by individual characteristics and related psychological aspects, such as motivation, or other factors, e.g. task difficulty (Seraganian et al. 1997, Boutcher and Boutcher 2006). In addition, potential effect of cognitive and affective processes fixed to past stressor should be taken into account in the context of application of the two consecutive tests. Repeated or chronic activation of the cognitive representation of psychological stressor, i.e. perseverative cognition, as manifested in worry and rumination, can result in prolonged sympathetic activation (Brosschot et al. 2006, 2010). The neural pathway of this mechanism seems to involve the disruption of the inhibitory control of subcortical structures by the prefrontal cortex resulting in the breakdown of a common reciprocal inhibitory cortical-subcortical neural circuit (Thayer and Lane 2002, Brosschot et al. 2006). The perseverative processes occur in the complex central autonomic network including the ACC and other structures which seem to play a key role in central processing of mental tasks, particularly the Stroop test (Benarroch 1993, MacLeod and MacDonald 2000, Hayward et al. 2004). On the other hand, the effect of the previous stressor can be diminished by various psychological factors, e.g. reduction of attention paid to 
the past stressor - cognitive distancing or changing the way the stressor is regarded - cognitive restructuring (Larsen and Christenfeld 2011). From this perspective, we could hypothesize that the onset of the second stress task could involve the effect of distraction with consequent minimization of reactive remnants of the Stroop test on the mental arithmetic task. Taken together, we assume complex neuro-psycho-physiological mechanisms influencing the cardiovascular sympathetic reactivity in response to different mental stressors. Further research is needed to elucidate these processes.

In terms of clinical application, differentiation of the effectors of sympathetic responses according to the nature of the stressor could reveal important novel findings about possible pathomechanisms of stressrelated diseases. We may expect that similar differences presented in this study could be found in response to reallife stressors. However, this assumption needs to be confirmed by independent study. Importantly, some pathological conditions, e.g. depressive or anxiety disorders with impaired attention and executive functioning, are associated with altered autonomic regulation at rest and in response to stress indicating potential increased cardiovascular risk (Castaneda et al. 2008, Tonhajzerova et al. 2010, 2012, Kemp et al. 2012). The detailed study of the cardiac and vascular responses to neuropsychological tests could help to elucidate the central-peripheral interaction within the stress and related health outcomes.

\section{Study limitations}

Our study included a relatively small homogeneous group of healthy young adults. The findings of this study need to be independently validated in larger sample including the control group undergoing the procedure without the mental tasks which could detect potential effect of environment and examining staff.

This study addressed the changes in cardiovascular sympathetic arousal to different stressors determined by the novel index of nonlinear analysis of short-term HRV - symbolic dynamics index (0V\%), and by the linear analysis of short-term systolic BP variability in low-frequency band (LF-SAP, 0.04-0.15 Hz) influenced predominantly by sympathetic division of autonomic nervous system. Since our study did not comprise direct invasive assessment of sympathetic neural activity, conclusions regarding exact quantitative neural signals in alone sympathetic branch of autonomic nervous system could not be drawn from the short-term $\mathrm{HR}$ and BP variability analysis. Further research in this field is needed.

\section{Conclusion}

In conclusion, we found distinct responses of the heart and vessels to two cognitive mental tasks using noninvasive complex assessment of the conceivable marker of sympathetic vascular regulation and potential cardio-sympathetic index. Further studies are needed to characterize and elucidate the pathways linking mental stress and mechanisms of specific cardiovascular effectors' response modulation.

\section{Conflict of Interest}

There is no conflict of interest.

\section{Acknowledgements}

This work was supported by Centre of Excellence for Perinatology Research I (ITMS 26220120016) (60\%), grant VEGA 1/0087/14 and Comenius University Grant $\mathrm{UK} / 261 / 2015$.

\section{References}

BARBOSA DF, PRADA FJ, GLANNER MF, NÓBREGA ODE T, CÓRDOVA CO: Cardiovascular response to Stroop test: comparison between the computerized and verbal tests. Arq Bras Cardiol 94: 507-511, 2010.

BEAUCHAINE TP, GATZKE-KOPP L, MEAD HK: Polyvagal Theory and developmental psychopathology: emotion dysregulation and conduct problems from preschool to adolescence. Biol Psychol 74: 174-184, 2007.

BEISSNER F, MEISSNER K, BÄR KJ, NAPADOW V: The autonomic brain: an activation likelihood estimation meta-analysis for central processing of autonomic function. J Neurosci 33: 10503-10511, 2013.

BENARROCH EE: The central autonomic network: functional organization, dysfunction, and perspective. Mayo Clin Proc 68: 988-1001, 1993.

BOUTCHER YN, BOUTCHER SH: Cardiovascular response to Stroop: effect of verbal response and task difficulty. Biol Psychol 73: 235-241, 2006. 
BROSSCHOT JF, GERIN W, THAYER JF: The perseverative cognition hypothesis: a review of worry, prolonged stress-related physiological activation, and health. J Psychosom Res 60: 113-124, 2006.

BROSSCHOT JF, VERKUIL B, THAYER JF: Conscious and unconscious perseverative cognition: Is a large part of prolonged physiological activity due to unconscious stress? J Psychosom Res 69: 407-416, 2010.

CASTANEDA AE, TUULIO-HENRIKSSON A, MARTTUNEN M, SUVISAARI J, LÖNNQVIST J: A review on cognitive impairments in depressive and anxiety disorders with a focus on young adults. $J$ Affect Disord 106: $1-27,2008$.

CHARKOUDIAN N, RABBITTS JA: Sympathetic neural mechanisms in human cardiovascular health and disease. Mayo Clin Proc 84: 822-830, 2009.

CHIDA Y, STEPTOE A: Greater cardiovascular responses to laboratory mental stress are associated with poor subsequent cardiovascular risk status: a meta-analysis of prospective evidence. Hypertension 55: 1026-1032, 2010.

CRAIG AD: Interoception: the sense of the physiological condition of the body. Curr Opin Neurobiol 13: 500-505, 2003.

CRITCHLEY HD, MATHIAS CJ, JOSEPHS O, O'DOHERTY J, ZANINI S, DEWAR BK, CIPOLOTTI L, SHALLICE T, DOLAN RJ: Human cingulate cortex and autonomic control: converging neuroimaging and clinical evidence. Brain 126: 2139-2152, 2003.

FALKNER B, ONESTI G, ANGELAKOS ET, FERNANDES M, LANGMAN C: Cardiovascular response to mental stress in normal adolescents with hypertensive parents. Hemodynamics and mental stress in adolescents. Hypertension 1: 23-30, 1979.

FECHIR M, SCHLERETH T, PURAT T, KRITZMANN S, GEBER C, EBERLE T, GAMER M, BIRKLEIN F: Patterns of sympathetic responses induced by different stress tasks. Open Neurol J 2: 25-31, 2008.

GIANAROS PJ, DERBYSHIRE SW, MAY JC, SIEGLE GJ, GAMALO MA, JENNINGS JR: Anterior cingulate activity correlates with blood pressure during stress. Psychophysiology 42: 627-635, 2005a.

GIANAROS PJ, MAY JC, SIEGLE GJ, JENNINGS JR: Is there a functional neural correlate of individual differences in cardiovascular reactivity? Psychosom Med 67: 31-39, $2005 \mathrm{~b}$.

GINTY AT, JONES A, CARROLL D, ROSEBOOM TJ, PHILLIPS AC, PAINTER R, DE ROOIJ SR: Neuroendocrine and cardiovascular reactions to acute psychological stress are attenuated in smokers. Psychoneuroendocrinology 48: 87-97, 2014.

GOLDSTEIN DS, BENTHO O, PARK MY, SHARABI Y: Low-frequency power of heart rate variability is not a measure of cardiac sympathetic tone but may be a measure of modulation of cardiac autonomic outflows by baroreflexes. Exp Physiol 96: 1255-1261, 2011.

GUZZETTI S, BORRONI E, GARBELLI PE, CERIANI E, DELLA BELLA P, MONTANO N, COGLIATI C, SOMERS VK, MALLIANI A, PORTA A: Symbolic dynamics of heart rate variability: a probe to investigate cardiac autonomic modulation. Circulation 112: 465-470, 2005.

HAYWARD G, GOODWIN GM, HARMER CJ: The role of the anterior cingulate cortex in the counting Stroop task. Exp Brain Res 154: 355-358, 2004.

JULIEN C: The enigma of Mayer waves: facts and models. Cardiovasc Res 70: 12-21, 2006.

KEMP AH, QUINTANA DS, FELMINGHAM KL, MATTHEWS S, JELINEK HF: Depression, comorbid anxiety disorders, and heart rate variability in physically healthy, unmedicated patients: implications for cardiovascular risk. PLoS One 7: e30777, 2012.

KLEIN E, MOELLER K, GLAUCHE V, WEILLER C, WILLMES K: Processing pathways in mental arithmetic evidence from probabilistic fiber tracking. PLoS One 8: e55455, 2013.

LARSEN BA, CHRISTENFELD NJ: Cognitive distancing, cognitive restructuring, and cardiovascular recovery from stress. Biol Psychol 86: 143-148, 2011.

LOVALLO WR: Do low levels of stress reactivity signal poor states of health? Biol Psychol 86: 121-128, 2011.

LUCINI D, NORBIATO G, CLERICI M, PAGANI M: Hemodynamic and autonomic adjustments to real life stress conditions in humans. Hypertension 39: 184-188, 2002a. 
LUCINI D, MELA GS, MALLIANI A, PAGANI M: Impairment in cardiac autonomic regulation preceding arterial hypertension in humans: insights from spectral analysis of beat-by-beat cardiovascular variability. Circulation 106: 2673-2679, 2002b.

LUCINI D, DI FEDE G, PARATI G, PAGANI M: Impact of chronic psychosocial stress on autonomic cardiovascular regulation in otherwise healthy subjects. Hypertension 46: 1201-1206, 2005.

MACDONALD AW, COHEN JD, STENGER VA, CARTER CS: Dissociating the role of the dorsolateral prefrontal and anterior cingulate cortex in cognitive control. Science 288: 1835-1838, 2000.

MACLEOD CM, MACDONALD PA: Interdimensional interference in the Stroop effect: uncovering the cognitive and neural anatomy of attention. Trends Cogn Sci 4: 383-391, 2000.

MALLIANI A, PAGANI M, LOMBARDI F, CERUTTI S: Cardiovascular neural regulation explored in the frequency domain. Circulation 84: 482-492, 1991.

MATTHEWS KA, WOODALL KL, ALLEN MT: Cardiovascular reactivity to stress predicts future blood pressure status. Hypertension 22: 479-485, 1993.

MCEWEN BS: Physiology and neurobiology of stress and adaptation: central role of the brain. Physiol Rev 87: 873904, 2007.

NEWLIN DB, LEVENSON RW: Pre-ejection period: measuring beta-adrenergic influences upon the heart. Psychophysiology 16: 546-553, 1979.

PAGANI M, LOMBARDI F, GUZZETTI S, RIMOLDI O, FURLAN R, PIZZINELLI P, SANDRONE G, MALFATTO G, DELl'ORTO S, PICCALUGA E, TURIEL M, BASELli G, CERUTTI S, MALLIANI A: Power spectral analysis of heart rate and arterial pressure variabilities as a marker of sympatho-vagal interaction in man and conscious dog. Circ Res 59: 178-193, 1986.

PORTA A, GUZZETTI S, MONTANO N, FURLAN R, PAGANI M, MALLIANI A, CERUTTI S: Entropy, entropy rate, and pattern classification as tools to typify complexity in short heart period variability series. IEEE Trans Biomed Eng 48: 1282-1291, 2001.

RAHMAN F, PECHNIK S, GROSS D, SEWELL L, GOLDSTEIN DS: Low frequency power of heart rate variability reflects baroreflex function, not cardiac sympathetic innervation. Clin Auton Res 21: 133-141, 2011.

REYES DEL PASO GA, LANGEWITZ W, MULDER LJ, VAN ROON A, DUSCHEK S: The utility of low frequency heart rate variability as an index of sympathetic cardiac tone: a review with emphasis on a reanalysis of previous studies. Psychophysiology 50: 477-487, 2013.

RIVERA SM, REISS AL, ECKERT MA, MENON V: Developmental changes in mental arithmetic: evidence for increased functional specialization in the left inferior parietal cortex. Cereb Cortex 15: 1779-1790, 2005.

SERAGANIAN P, SZABO A, BROWN TG: The effect of vocalization on the heart rate response to mental arithmetic. Physiol Behav 62: 221-224, 1997.

THAYER JF, LANE RD: A model of neurovisceral integration in emotion regulation and dysregulation. $J$ Affect Disord 61: 201-216, 2000.

THAYER JF, LANE RD: Perseverative thinking and health: neurovisceral concomitants. Psychol Health 17: 685-695, 2002.

TONHAJZEROVA I, ONDREJKA I, JAVORKA K, TURIANIKOVA Z, FARSKY I, JAVORKA M: Cardiac autonomic regulation is impaired in girls with major depression. Prog Neuropsychopharmacol Biol Psychiatry 34: 613-618, 2010.

TONHAJZEROVA I, ONDREJKA I, CHLADEKOVA L, FARSKY I, VISNOVCOVA Z, CALKOVSKA A, JURKO A, JAVORKA M: Heart rate time irreversibility is impaired in adolescent major depression. Prog Neuropsychopharmacol Biol Psychiatry 39: 212-217, 2012.

VANDERHASSELT MA, DE RAEDT R, BAEKEN C, LEYMAN L, D'HAENEN H: The influence of rTMS over the left dorsolateral prefrontal cortex on Stroop task performance. Exp Brain Res 169: 279-282, 2006.

VISNOVCOVA Z, MESTANIK M, JAVORKA M, MOKRA D, GALA M, JURKO A, CALKOVSKA A, TONHAJZEROVA I: Complexity and time asymmetry of heart rate variability are altered in acute mental stress. Physiol Meas 35: 1319-1334, 2014. 
WAGER TD, WAUGH CE, LINDQUIST M, NOLL DC, FREDRICKSON BL, TAYLOR SF: Brain mediators of cardiovascular responses to social threat: part I: Reciprocal dorsal and ventral sub-regions of the medial prefrontal cortex and heart-rate reactivity. Neuroimage 47: 821-835, 2009.

ZANSTRA YJ, JOHNSTON DW: Cardiovascular reactivity in real life settings: measurement, mechanisms and meaning. Biol Psychol 86: 98-105, 2011.

ZHANG R, IWASAKI K, ZUCKERMAN JH, BEHBEHANI K, CRANDALL CG, LEVINE BD: Mechanism of blood pressure and R-R variability: insights from ganglion blockade in humans. J Physiol 543: 337-348, 2002. 